\title{
- Laço social Na \\ CONSTRUÇÃO IDENTITÁRIA DO ALCOólico ANÔNIMO
}

Raul Max Lucas da Costa

Centro Universitário Dr. Leão Sampaio (Unileão)

\section{Leonardo Danziato}

Universidade de Fortaleza (Unifor)
Recebido em: 19/07/2020

$1^{a}$ revisão em: 15/08/2021

$2^{a}$ revisão em: 24/09/2021

Aceito em: 12/10/2021

\section{RESUMO}

A diversidade de grupos anônimos no âmbito social compõe um panorama maior de coletivos identitários que reivindicam sua diferença e distinção social. Considerando a primazia histórica da Irmandade Alcoólicos Anônimos (AA), este artigo discute a construção identitária e social do alcoólico anônimo. Recorremos à literatura oficial da Irmandade como fonte de dados e à teoria psicanalítica como referencial teórico para a análise dos resultados. Constatamos que a construção identitária do alcoólico anônimo se estabelece a partir de um engajamento a Irmandade, sendo seu funcionamento pautado nos ideais de fraternidade, anonimato e abstinência alcoólica. Entre os AA, a identificação sintomática com o alcoolismo pressupõe o vínculo fraternal, funcionando como uma reparação imaginária no trabalho de construção do alcoolista anônimo. Concluímos que a produção identitária "alcoólico anônimo" consiste na adesão a uma nova forma de vida, cujos efeitos são de segregação ao laço social e de alienação ao Outro institucional.

Palavras-chave: alcoólatras anônimos; teoria psicanalítica; identificação; subjetivação; sociabilidade. 


\title{
THE SOCIAL BOND IN THE CONSTRUCTION OF THE ANONYMOUS ALCOHOLIC'S IDENTITY
}

\begin{abstract}
In contemporaneity, the presence of several anonymous groups composes a diverse set of identity groups that claim their difference and distinction. Considering the historicity of the Brotherhood of Alcoholics Anonymous (AA), this article analyzes the identity construction of the anonymous alcoholic and its relationship with the social bond. We used the official literature of the Brotherhood as a data source and the psychoanalytic theory as a theoretical reference for the analysis of the results. We find that the identity construction of the anonymous alcoholic establishes, in principle, from an institutional engagement to the $A A$, being its operation based on the ideals of brotherhood, anonymity and alcohol abstinence. Among AA the symptomatic identification with the alcoholism disease occurs concomitant to the establishment of the fraternal bond that functions as an imaginary and egoic repair for the alcoholic in his work of identity production. We conclude that the "anonymous alcoholic" identity construction is equivalent to the purpose of the therapeutic proposal of AA that consists in the adhesion to a new way of life, whose effects are of segregation to the social bond and of alienation to the Institutional Other.
\end{abstract}

Keywords: alcoholics anonymous; psychoanalytic theory; identification; subjectivity; sociability. 


\section{EL VÍNCULO SOCIAL EN LA CONSTRUCCIÓN DE LA IDENTIDAD DEL ALCOHÓLICO ANÓNIMO}

\section{RESUMEN}

En nuestra era contemporánea, la presencia de innumerables grupos anónimos constituye un panorama diverso de grupos de identidad que reclaman su diferencia y distinción. Considerando la primacía histórica de la Hermandad Alcohólicos Anónimos (AA), este artículo discute la construcción de identidad del alcohólico anónimo y su relación con el vínculo social. Utilizamos la literatura oficial de la Hermandad como fuente de datos y la teoría psicoanalítica como marco teórico para el análisis de resultados. Descubrimos que la construcción de la identidad del alcohólico anónimo se establece, al principio, a partir de un compromiso institucional con $A A$, y su funcionamiento se basa en los ideales de fraternidad, anonimato y abstinencia de alcohol. Entre los $A A$, la identificación sintomática con el alcoholismo de la enfermedad ocurre simultáneamente con el establecimiento del vínculo fraterno que funciona como una reparación imaginaria y egoica para el alcohólico en su trabajo de construcción de identidad. Concluimos que la producción de identidad "alcohólica anónima" es equivalente al propósito de la propuesta terapéutica de AA, que consiste en adherirse a una nueva forma de vida, cuyos efectos son la segregación del vínculo social y la alienación del Otro institucional.

Palabras clave: alcohólicos anónimos; teoría psicoanalítica; identificación; subjetividad; sociabilidad. 


\section{INTRODUÇÃO}

É notório no âmbito da clínica psicanalítica e na vida cotidiana que os diagnósticos médicos, sobretudo os psiquiátricos, vêm sendo utilizados para nomear novas referências identitárias. Enunciados como "sou depressivo", "sou adicto", "sou bipolar", servem como referências subjetivantes promovendo uma ultrapassagem para o que seria a priori um recurso da terapêutica médica, necessário a um prognóstico (diagnosticar para tratar), para a constituição de identidades pessoais e coletivas (Barros \& Danziato, 2014).

Essa junção entre diagnóstico e identidade parece aludir a novos arranjos sociais em uma dimensão mínima. Desde a formação de grupos identitários regidos por regras de convívio, ao modo de um pequeno "comitê de ética", denunciando o declínio do Outro social (Miller, 2010), até a militância pelo reconhecimento social e por direitos das minorias sociais, assistimos a uma verdadeira fragmentação do laço social pautado na segregação (Askofaré, 2009).

Diferente da pesquisa socioantropológica que privilegia o termo de identidade, em psicanálise predomina a referência ao conceito de identificação, servindo a pesquisa psicanalítica como ferramenta teórica central de análise para a formações de massa e de grupos artificiais no âmbito social. Por identificação, entende-se uma operação de constituição subjetiva sempre contínua, considerando a articulação entre o sujeito, o grande Outro e a perda do objeto. Freud (1921/2011) apresenta de forma mais sistemática este conceito em sua discussão sobre a constituição das massas sociais. Dedicaremos mais detalhes sobre a questão mais adiante. Por ora, nos interessa apresentar que as massas, na perspectiva freudiana, pressupõem um líder, figura que servirá como traço identificatório para cada sujeito na massa funcionando como um ideal do Eu e sendo alvo de um enamoramento coletivo. Neste sentido, ocorre uma diferença básica entre as massas espontâneas e as artificiais, caracterizadas por sua organização institucionalizada.

Um grupo identitário pioneiro em sua constituição em torno de uma categoria médica foi a Irmandade Alcoólicos Anônimos (AA). Instituição fundada em 1935 e, atuante em nossos dias, tem como proposta central oferecer um tratamento para - alcoolismo através de um programa espiritual de doze passos (Alcoólicos Anônimos, 2010). Desde sua origem, uma das premissas para a prática de seu método terapêutico é aceitação de que o alcoolismo é uma 'doença' e, consequentemente, de que há doentes alcoólicos. Tal construção identitária dos AA já foi objeto de várias pesquisas no campo das ciências sociais (Campos, 2010; Mota, 2004; Tadvald, 2006; Trois, 1998). Em todas elas, são destacados os elementos simbólicos da Irmandade: o rito da fala nas reuniões, a 'oração da serenidade', o tempo da sobriedade marcado pelos chaveiros coloridos, a crença no Poder Superior, as tradições e os conceitos de base e a experiência modelo dos fundadores Bill Wilson e Robert Smith. 
Nossa proposta no presente artigo é analisar a relação do enlace social entre os AA e a formação identitária 'alcoólico anônimo' a partir de uma análise discursiva da chamada "literatura de AA" tendo como referencial teórico a psicanálise em sua vertente freudiana e lacaniana. Nossa hipótese é de que o laço fraterno e a estruturação institucional dos AA são as condições fundamentais de sustentação de uma nomeação identitária não referenciada em um líder personalizado, mas a um ideal de sobriedade.

Recorrer a um diagnóstico é uma maneira de nomear a condição de mal-estar do sujeito na cultura (Dunker, 2015). Tal nomeação tem como efeito o declínio da experiência de singularidade em favor de uma forma de vida patológica. Se podemos analisar a segregação dos tempos atuais como uma "lógica do condomínio" como sugere Dunker (2015), é possível ler às regras cotidianas em torno das prescrições médicas, dietas e exercícios físicos enquanto componentes, em seu conjunto, de uma nova dietética como forma de vida. No caso dos AA, a dietética em questão é a busca constante da sobriedade, ou seja, uma vida abstinente do consumo alcoólico.

Perdura entre os AA uma concepção pragmática do alcoolismo como 'doença alérgica' e individual, cujos aspectos subjetivos são reconhecidos pela dominância do objeto álcool sobre o sujeito e pela ruptura do alcoolista com seus laços de sociabilidade, sobretudo, os familiares e os de trabalho. A premissa doutrinária de recuperação alcoólica dos AA parte do princípio de que somente um 'alcoólico' é capaz de auxiliar outro 'alcoólico'. Além desse laço com o outro semelhante faz-se necessário a constituição alteritária com um Outro, lugar a priori denominado como 'Poder Superior', mas que deve ser nomeado de forma particular pelo alcoólico anônimo (Costa, 2020).

Nos chama à atenção nesse trabalho de produção subjetiva dos AA a ocultação da liderança e a primazia ao laço fraterno em torno da perspectiva do anonimato. Mais do que uma precaução sigilosa do nome próprio de cada um dos membros de $A \mathrm{~A}$, o anonimato é definido como uma condição que deve ser assumida pelo alcoólico em recuperação de aniquilação de seu Eu, fator determinante em sua relação destrutiva com a bebida (AA, 2010).

\section{MÉTODO}

Como proposta metodológica, realizamos uma pesquisa bibliográfica da chamada "literatura de $A A^{\prime}$ que consiste no conjunto de publicações da Irmandade: livros, livretos, folhetos e informativos. Privilegiamos as fontes de pesquisa relacionadas ao nosso objeto de estudo, quais sejam, os livros Alcoólicos Anônimos (2010), livro fundamental da doutrina dos $\mathrm{AA}$, Os Alcoólicos Anônimos Atingem a maioridade (2009), obra que apresenta a história de institucionalização dos AA e, por fim, $\mathrm{Na}$ Opinião de Bill, livro escrito pelo o principal fundador dos AA, discorrendo sobre a experiência de vida comunitária na Irmandade. Para análise dos dados da pesquisa, utilizamos a teoria psicanalítica em sua vertente freudiana e lacaniana. Adotamos 
como procedimento de análise uma aproximação entre a teoria psicanalítica e a análise de discurso francesa (Dunker, et alli, 2016). Tal indicação investigativa se vale da tese de que a psicanalíse por si só é uma análise de discurso. Ao confrontar, portanto, a literatura de AA com a teoria psicanalítica, encontramos uma possibilidade de pesquisa frutífera, privilegiando os elementos analíticos de uma análise discursiva: a linguagem, o contexto histórico e a ideologia (Orlandi, 2005).

Nossa leitura do material selecionado sobre a sociabilidade dos AA, elegeu três grandes categoriais de análise: instituição, fraternidade e dependência. Tais categorias se articulam ressaltando o aspecto de coletividade como prioridade na construção identitária do alcoólico anônimo. A seguir, iremos desenvolver as três categorias escolhidas com o referencial teórico psicanalítico.

\section{RESULTADOS E DISCUSSÕES}

\section{OS AA COMO INSTITUIÇÃO}

Com relação às problemáticas relacionadas ao trabalho clínico nas instituições, Lebrun (2009) enfatiza a instituição como um conceito, inclusive já objeto de análises sociológicas como a empreendida por Durkheim. Tal consideração sobre a estrutura institucional como uma questão teórica conceitual se apresenta de grande pertinência, pois desconstrói a tendência à naturalização do funcionamento institucional. Para o autor, a instituição pressupõe uma estruturação baseada nos seguintes aspectos: a autoridade do arché, a hierarquização e a tradição.

A palavra arché remete ao antigo, ao primeiro. A primazia dos mais velhos é um dos fundamentos de qualquer instituição. Aqueles que funcionam como arché têm a função de instituir e preservar. Temos com isso uma dupla função: estabelecer o funcionamento de uma coletividade e conservar seus princípios. Entre os AA é notório que o instituído parte de seus fundadores Bill Wilson e Robert Smith e dos demais pioneiros. Desses, o nome de Bill Wilson (ou simplesmente Bill W., a ocultação do sobrenome respeita o princípio do anonimato) é o mais destacado. É o seu relato pessoal que prevalece no livro Alcoólicos Anônimos (2010), cuja publicação foi fundamental para o estabelecimento da Irmandade. O despertar espiritual de Bill Wilson serviu como referência para a construção dos doze passos. Boa parte dos livros e livretos que compõem a 'literatura de AA' são de sua autoria. Os outros livros estendem e replicam relatos infindáveis, corroborando sempre com o programa espiritual instituído, basicamente por Bill Wilson. As revistas de AA de circulação nacional e internacional repetem quase a exaustão os doze passos, os doze conceitos e as doze tradições, buscando atualizá-los e contextualizá-los.

Embora os AA, se apresentem como uma irmandade, sem lideranças que possam Ihe direcionar e representar, em sua prática institucional é possível identificar uma complexa organização que se utiliza de diversas representatividades. Enquanto instituição de proporções globais, há uma divisão geográfica de sua organização 
somada uma espécie de gradus representativo. No Brasil, a Irmandade se organiza em regiões e distritos. Em cada subárea são eleitos periodicamente representantes locais, necessários para a composição dos eventos nacionais e internacionais. No espaço citadino, os grupos se dividem entre os que promovem reuniões e estudam a literatura de AA. Em cada cidade há um escritório de AA que tem a função de registrar e gerir tais grupos. Não são apenas os alcoolistas anônimos que integram os AA. Uma outra forma de aderência institucional é tornar-se um colaborador. Assim, têm-se os 'não alcoólicos' (simpatizantes), em geral profissionais de saúde (médicos, psicólogos e demais categorias) e líderes religiosos que compõem a categoria 'amigos de $\mathrm{AA}^{\mathrm{A}}$ '.

No que se refere à tradição como um dos elementos constituintes de uma instituição, entre os $\mathrm{AA}$, ela possui um valor crucial. A composição das doze tradições e o recurso à memória da experiência fundacional doam aos AA uma aura conservadora e histórica. As tradições são invenções, cuja funcionalidade primordial é erigir uma identidade coletiva (Hobsbawm \& Ranger, 1984). A temporalidade entre os AA é marcada por um conflito na fronteira entre a memória e a história. De um lado a repetição ininterrupta dos jargões, dos princípios, das preces, dos ritos de passagem de manutenção da sobriedade. Por outro, a afinidade com o arquivo, o apreço as histórias fundacionais dos diversos grupos, as construções narrativas de vida sempre demarcadas pelo antes do período da ativa para o depois do alcance da sobriedade.

Nesse sentido, além dos doze passos, os AA instituíram uma lista de doze tradições que resume os preceitos institucionais da Irmandade:

1- Nosso bem-estar comum deve estar em primeiro lugar; a recuperação individual depende da unidade de AA.

2- Para nosso propósito de grupo, há somente uma autoridade suprema - um Deus amantíssimo que Se manifesta em nossa consciência de grupo. Nossos líderes são apenas servidores de confiança; não governam.

3- O único requisito para ser membro de AA é o desejo de parar de beber.

4- Cada grupo deve ser autônomo, salvo em assuntos que digam respeito a outros grupos ou a AA em seu conjunto.

5- Cada Grupo é animado por um único propósito primordial - o de transmitir sua mensagem ao alcoólico que ainda sofre.

6- Nenhum grupo de AA deverá jamais emprestar o nome de AA, endossar ou financiar qualquer sociedade ou empreendimento alheio à Irmandade, a fim de que problemas de dinheiro, propriedade e prestígio não nos afastem do nosso objetivo primordial.

7-Todos os Grupos de AA deverão ser totalmente autossuficientes, rejeitando quaisquer doações de fora. 
8- Alcoólicos Anônimos deverá manter-se sempre nãoprofissional, embora nossos centros de serviços possam contratar funcionários especializados.

9- AA como tal, jamais deverá ser organizado; podemos, porém, criar juntas ou comitês de serviço diretamente responsáveis perante aqueles a quem prestam serviços.

10- Alcoólicos não opina sobre questões que lhe são alheias; portanto, o nome de AA jamais deverá aparecer em controvérsias públicas.

11- Nossa política de relações públicas baseia-se na atração em vez da promoção; precisamos sempre manter o anonimato pessoal na imprensa, rádio e filmes.

12- O anonimato é o alicerce espiritual das nossas Tradições, lembrando-nos sempre da necessidade de colocar os princípios acima das personalidades (grifos nossos) (AA, 2017, pp.335-36).

Em seu conjunto, as doze tradições estabelecem a hegemonia da fraternidade sobre a individualidade, a relação com o dinheiro e a posição política da Irmandade no âmbito social. O propósito maior desses preceitos é manter o funcionamento institucional através do estabelecimento de uma cultura de convívio mútuo.

Um conceito que atravessa tais tradições é o de anonimato. Para além de um sigilo social sobre a própria condição de alcoólico em recuperação, o anonimato é definido como um pilar espiritual que preza pela sobreposição dos princípios de coletividade sobre a personalidade de cada um. Tal concepção pode ser entendida como a própria a abstinência da Irmandade nos debates públicos, inclusive sobre as políticas de tratamento do alcoolismo.

\section{FRATERNIDADE E MASSA}

Podemos situar a questão da fraternidade como oriunda dos ideais modernos inaugurados pela Revolução Francesa de 1789. A Modernidade não foi só a era histórica da ascensão da noção de indivíduo, mas foi também um momento de transição dos valores religiosos e aristocráticos para a vida civil baseada no estado de direito. Importante destacar essa distinção entre o laço fraterno cristão e o laico (Kehl, 2000).

No contexto moderno, a liberdade se constitui como um dos principais ideais sociais da vida civil. A partir disso, ser ou não ser livre se apresenta como uma questão filosófica e jurídica para o homem moderno (Figueiredo, 2007). Não à toa a maior punição para este seja a prisão celular, ou seja, a privação de sua liberdade (Foucault, 2007).

Desde então, a fraternidade figura ao lado da liberdade e da igualdade como um dos ideais da vida civilizada. Contudo, a formação dos estados nacionais modernos não garantiu a concretização do laço civilizatório. Desde a Declaração Universal 
dos Direitos do Homem até a declaração Universal dos Direitos Humanos (1948), assistimos o confronto sanguinário de exploração econômica e a expansão da guerra como correlato da política. Kehl (2004, p.29) sintetiza de forma pertinente essa questão ao afirmar que "os direitos humanos não refletem a natureza humana".

Freud, enquanto crítico mordaz da modernidade e de suas instituições, destaca o laço fraterno em três momentos de sua obra: Totem e Tabu: algumas concordâncias entre a vida psíquica dos homens primitivos e dos neuróticos (Freud, 1912-13/2012), Psicologia das Massas e Análise do Eu (Freud, 1921/2011) e o Mal-estar na Civilização (Freud, 1930/2010).

Interessante notar nestas obras supracitadas que na vida coletiva, da qual destacamos o laço fraterno, as manifestações afetivas são decisivas: a ambivalência afetiva da horda com seu pai, a massa enamorada pelo líder e hostil ao inimigo e a forçosa Regra de Ouro do cristianismo (ama teu próximo como a ti mesmo) como uma moral civilizada. Não se trata propriamente de uma primazia dos afetos, mas de apontar para a ocorrência da identificação. Vale aqui ressaltar a clássica definição freudiana do conceito: "é a relação afetiva mais antiga que o sujeito constitui com o outro" (Freud, 1921/2011, p.60). O interesse freudiano nos estudos antropológicos com o intuito de fazer uma analogia da vida primitiva com a vida do neurótico, o fez perceber a importância da ordem simbólica na constituição recíproca do sujeito e do laço social.

O assassinato do Pai da Horda, mito moderno conforme Lacan (1992), revela o surgimento do laço entre os irmãos. Como mito, é ele revelador de uma verdade semi-dita com a função de elaborar, através da ficção, um sentido diante do real. O mito difere, portanto, da verdade histórica que necessita marcar cronologicamente os acontecimentos.

Por deter o domínio sobre a horda e a posse de todas as fêmeas, o pai (objeto de amor e ódio) é morto após uma rebelião de seus filhos que unidos cometem o ato assassínio. A morte do pai convoca a horda a fazer um duplo arranjo: o laço fraterno e a construção simbólica do totem em função do sentimento de culpa. Destacamos assim desse mito freudiano dois tempos da formação da fratria totêmica: um primeiro, que corresponde ao enlaçamento fraterno em torno ódio, anterior ao ato homicida. Mais do que o amor, parece ser o ódio o afeto que produz mais consistência ao laço coletivo. O segundo tempo, seria o de um reconhecimento da operatividade do irmão, 'função fraterna' conforme Kehl (2000), após o ato, na construção de um pai simbólico a qual não se pode matar, com exceção do banquete totêmico onde ocorre a identificação com o traço paterno via incorporação.

Anterior a Freud, o tema do laço fraterno já ocupava a pesquisa antropológica como a organização totêmica analisada por Frazer. A designação fratria, por exemplo, é antiga e faz referência ao laço familiar constituído mais pela referência simbólica do que pelo elo sanguíneo. A novidade freudiana no estudo do 
totemismo foi supor a origem da Lei simbólica fundamenta na proibição do incesto e do parricídio e sua relação com a clínica do sujeito neurótico. Há, na leitura freudiana, uma equivalência entre a vida primitiva e a infância. Os agrupamentos humanos do passado anteriores ao processo civilizatório equivalem às crianças que atravessam o complexo edípico e são civilizadas pela Kultur (cultura/civilização).

Um dos aspectos fundantes da fratria seria o de fazer operar a semelhança na diferença. O irmão ao mesmo tempo em que é o semelhante é também o rival e objeto do ciúme narcisista (Kehl, 2000). Daí a possibilidade do fratricídio e da competição entre irmãos.Tal fato é lido por Lacan (2003) como um dos complexos familiares: o de intrusão.

A massa freudiana seria, portanto, o protótipo da fratria contemporânea. Enquanto crítica à psicologia social de sua época (Assoun, 2008), Freud em Psicologia das massas e análise do Eu (1921), realiza um estudo crucial sobre a gênese das massas e sua relação com o Eu em um momento histórico de reconfigurações governamentais como a Revolução Russa de 1917 e o surgimento dos totalitarismos (Roudinesco, 1998). Lacan (2008) situa a própria institucionalização da psicanálise como o grande elemento contextual dessa obra freudiana. Acreditamos que as discussões etimológicas sobre conceito de massa, camuflam o debate freudiano sobre a formação do Eu na coletividade. Em outras palavras os comentários à obra destacam mais a psicologia das massas e costumam esquecer a análise do Eu.

O que se passa com as massas? Diferente dos achados da pesquisa psicológica e sociológica, Freud observa o lugar crucial do traço unário e da identificação nas formações grupais e das multidões. O termo alemão Massen serve para denotar tanto os grupos organizados como as grandes massas. O destaque freudiano reside na relação libidinal da massa com seu líder, questão negligenciada pelos sociólogos e psicólogos. Diante do líder, as massas organizadas (cujos exemplos maiores são a igreja e o exército) assumem uma posição de enamoramento típica do hipnotizado frente ao hipnotizador.

A constatação freudiana vai mais além e revela que nessa relação temos nada mais nada menos que uma revivescência da horda primeva. A massa submissa se dispõe a obedecer seu líder/pai. Ocorre aí uma elevação dos afetos e um declínio da razão. Dessa revivescência vemos mais uma vez uma temporalidade que une passado e presente tal e qual a apresentada em Totem e Tabu entre a vida primitiva e a vida neurótica.

Será a partir dessa relação fundamental que temos a primeira fonte de identificação no interior do Complexo de Édipo: a que ocorre do sujeito com o pai. Com a mãe se estabelece uma relação de apoio enquanto a relação de objeto é com a figura paterna, admirado e exemplo para a criança.

A segunda fonte de identificação consiste na formação dos sintomas neuróticos. Freud (1921/2010) ressalta um aspecto do Caso Dora, a situação de uma tosse 
contínua de sua paciente. O trabalho analítico lhe revelou a relação desta crise sintomática com a tosse do pai. Disso, é possível constatar a função da identificação como uma substituição a relação de objeto anterior, daí Freud considerar um aspecto regressivo na identificação. Essa afirmação coloca a identificação como uma operação para lidar com a falta do objeto depois de sua acessibilidade. É esse o fato que parece ocorrer na perda de um objeto de amor, ou seja, com impossibilidade de possuí-lo novamente, ocorrer a identificação com os traços do objeto via introjeção.

Como terceira fonte de identificação Freud nos apresenta a do tipo histérico. Esta é caracterizada por sua manifestação via contágio, ou ainda, por 'infecção psíquica', ocorrência comum no âmbito coletivo quando um traço específico serve de referência aos demais. É exemplar nesse sentido, a suposição freudiana de uma garota residente de um pensionato que recebe uma carta de seu namorado terminando o relacionamento. Enquanto ela pranteia sua perda, todas suas colegas, via identificação histérica, põem-se também a chorar (Freud, 1920/2011).

Ao fim, temos a constatação de um elemento formador das massas: o ideal do Eu. Este pode substituir a função do líder e servir como elemento unificador de uma coletividade. Teríamos assim a substituição de um objeto, alvo de investimento libidinal, por um ideal do Eu. Este é o momento crucial de sua reflexão sobre as massas, seus efeitos na constituição do Eu. Muitas podem ser as massas que o sujeito busca se agregar. Vale ressaltar que nesse momento Freud não tinha ainda o conceito de supereu, categoria teórica formalizada em uma obra sequencial a Psicologia das Massas, o Eu e o Isso (1923). Haja vista o conceito de supereu incluirá a referência ao ideal do Eu.

Com relação a uma pretensa tendência gregária fundamentada na teoria biológica do instinto gregário, a elucidação freudiana revela que na verdade há uma tendência não à unidade e sim à segregação via narcisismo. Daí a conclusão corrente que o elemento unificador de um grupo é justamente a rivalidade, ou ainda, a inimizade com o próximo. Os vizinhos são sempre rivais. Tal lógica se concretiza nas políticas totalitárias que fortalecem suas massas construindo um inimigo a ser combatido e eliminado.

Aqui vale apresentar uma interrogação com relação à organização dos AA. Seria a Irmandade em questão uma massa sem líder? A resposta imediata é de que temos funcionando um ideal do Eu da sobriedade. O elo de um alcoólico a outro, o elemento unificador da fratria, ocorre a partir do estabelecimento da abstinência alcoólica como o objetivo maior da Irmandade. Trata-se de um ideal, pois a própria literatura de AA mostra a recaída como um fato recorrente e que faz parte da prática dos doze passos. A exortação literária é de justamente não segregar ou excluir o companheiro que recaiu e voltou a buscar a sobriedade.

A relação fraterna entre os AA seria isenta de conflitos? Vegh (2005) dedica um de seus livros a refletir sobre o lugar do próximo a partir do enigmático mandamento cristão: "ama o teu próximo como a ti mesmo". Conclui que a presença do outro 
semelhante revela a possibilidade de ser gozado pelo outro, nas palavras de Lacan: o próximo é a iminência de ser gozado. O paradoxo é que a invocação do outro se apresenta como uma condição diante do mal-estar. O "a ti mesmo" do mandamento não equivale ao Eu, e sim a ao ideal de amor.

É conhecido o comentário freudiano pouco otimista sobre a ética cristã no final de sua obra O Mal-estar na Civilização. A construção cultural da ética é vista como uma tentativa forçada de manter uma convivência com o outro que raramente dedica amor ao próximo sendo mais recorrente uma relação de agressividade.

Retomando a questão sobre a ausência ou não de conflitos na instituição $A A_{\text {, }}$ consideramos importante situar a operatividade do significante "irmandade" entre os AA. De início, a apresentação social dos AA como uma irmandade não anula os efeitos hierárquicos de sua constituição enquanto instituição. Embora seja corrente um membro chamar o outro de companheiro(a) (e não de irmão, designação comum entre os evangélicos), é evidente que a autoridade dos mais velhos, geralmente os padrinhos dos recém chegados, produz um desnível em uma pretensa relação horizontal. Eleger o laço fraterno artificial como forma de organização e a irmandade como nomeação institucional nos chama a atenção, considerando seu contexto de surgimento em meio à predominância de corporações, empresas, fundações e associações diversas.

Uma resposta possível sobre o porquê do nome Irmandade reside na própria doutrina literária dos $A A$ que consiste na crença de que somente um alcoolista pode ajudar outro. Toda história fundacional de AA, constantemente rememorada em sua literatura, é a suposta confirmação de que somente um 'doente alcoólico' em recuperação é capaz de ajudar a um outro que sofre e de que esta é a maneira mais eficaz de tratamento do alcoolismo. Implicitamente, outro princípio se apresenta nesse enunciado: para cessar de beber, ou seja, para alcançar a abstinência o doente alcoólico deve desejá-la. A iniciativa deve partir dele. Não se trata, portanto, de uma terapêutica compulsória. Um slogan de divulgação da Irmandade, bastante difundido na mídia televisiva, era: "se seu problema é beber o problema é seu, mas se seu problema é parar de beber o problema é nosso".

Desde o início, o programa de doze passos pressupõe um apelo ao outro semelhante e a um Outro de poder. No laço fraterno entre os AA a referência a um grupo de AA específico, ou ainda, a Irmandade em sua totalidade pode servir como um Poder Superior:

É no grupo que se aprende a compartilhar esse "Deus horizontal", que se 'manifesta através do depoimento de um companheiro'. Em outras palavras: é no grupo que os AA se ajudam mutuamente, integrando-se novamente ao círculo da troca, fundamento de todo laço social. É através da troca de experiências que o indivíduo reitera sua condição de doente, ouvindo a voz desse "Deus horizontal", que fala por meio das 
"boas palavras" trocadas cotidianamente nas reuniões de recuperação (Campos, 2010, p.87).

Vemos operar dessa forma a função da fala e da palavra. Se a necessária invocação do outro é uma das características da relação do sujeito com o seu próximo (Vegh, 2005), entre o AA esse apelo consiste em uma premissa fundamental dos doze passos resultando na construção de uma dupla alteridade: vertical (Outro de poder) e horizontal (outro semelhante). Mesmo na concepção da instituição AA como Poder Superior, faz-se necessário a criação de um lugar Outro para uma passagem do gozo ao alcoolista para uma posição alienante no Outro. Há, portanto, uma mudança de posição solitária (de gozo com a bebida alcoólica) para uma fraterna (de manutenção da abstinência alcoólica):

A vida adquire um novo sentido em AA. Ver pessoas se recuperarem, vê-los ajudarem os outros, ver desaparecer a solidão, ver crescer uma fraternidade ao redor de você, ter um grande número de amigos - essa é uma experiência que não deve ser perdida (AA, 2017, p.90).

\section{DEPENDÊNCIA E IDENTIFICAÇÃo}

O que se busca na prática doutrinária da Irmandade é, portanto, uma nova dependência. Em vez do álcool passa-se a depender de um Poder Superior (concebido e nomeado de forma singular pelos membros), considerado como o único ente capaz de operar como uma sustentação da abstinência através de uma gradual transformação de vida: "Tivemos que deixar de fazer o papel de Deus. Isso não funcionou. Decidimos que dali por diante, nesse drama da vida, Deus ia ser nosso Diretor. Ele seria o Chefe: nós, os Seus agentes" (AA, 2017, p.67)

Entre os AA a dependência ao Poder Superior é positivada e almejada. Tal fato revela que o cerne da funcionalidade da Irmandade é a constante comprovação de que o alcoólico (antes bebedor ativo e depois abstinente em recuperação), é um dependente. A diferença consiste na concepção de que a dependência à bebida alcoólica é destrutiva e a dependência ao Poder Superior é construtiva. Daí uma passagem da adicção ao objeto a posição de alienação ao Outro.

Qualquer que seja a gravidade da obsessão pelo álcool, felizmente descobrimos que ainda podem ser feitas outras escolhas vitais. Por exemplo, podemos admitir que somos impotentes pessoalmente perante o álcool; que a dependência de um 'Poder Superior' é uma necessidade, mesmo que esta seja simplesmente uma dependência de um grupo de AA (AA, 2017, p. 68). 
A formalização do conceito de alienação no ensino lacaniano recebeu um lugar privilegiado no Seminário Os Quatro Conceitos Fundamentais da Psicanálise (Lacan 1998). Tal constructo conceitual consiste em mais uma apropriação lacaniana da filosofia, especificamente de suas leituras sobre Hegel e Marx. Lacan doa ao conceito de alienação uma significação psicanalítica tornando-o uma ferramenta conceitual importante para a teorização sobre a constituição do sujeito e para a prática clínica.

A alienação indica a dependência do sujeito ao significante. Continuando uma discussão apresentada em seu seminário anterior, A Angústia (Lacan, 2010), sobre a diferença entre o significante e o objeto $a$, Lacan destaca que sujeito se constitui no campo do Outro. Daí podemos considerar dois campos distintos: o do sujeito e o do Outro, sendo a cadeia significante próprio deste último. A relação do sujeito com o Outro é marcada uma hiância e por uma circularidade assimétrica. Lacan recorre ao símbolo da punção $\diamond$ para marcar o movimento circular da alienação, ressaltando o véu (a base do losango) como a primeira operação de fundação do sujeito: "... a alienação consiste nesse véu que (...) condena o sujeito a só aparecer nessa divisão que venho, me parece, de articular suficientemente ao dizer que se ele aparece de um lado como sentido, produzido pelo significante, do outro ele aparece como afânise" (Lacan,1998, p.199).

Por afânise entende-se o efeito de desaparecimento do desejo diante do Outro. A sobreposição lógica entre o sujeito e o Outro corresponde a premissa matemática da reunião.

É perceptível que um dos efeitos dessa posição dependente é o próprio apagamento subjetivo em favor da massa. A unidade da Irmandade, seja nos pequenos grupos e na instituição maior, é ameaçada pelas manifestações de hostilidade e indignação, consideradas fatores destruição. A literatura apela para uma não hostilização do outro semelhante na ocasião de falhas ou recaídas:

Se houver muita raiva, a unidade e o propósito estão perdidos. Se também houver muita indignação 'justificada', o grupo pode se desintegrar, ele pode até morrer. É por isso que evitamos controvérsia. Por isso também que não prescrevemos castigos para os erros, não importa sua gravidade. Na verdade, nenhum alcoólico, por nenhuma razão, pode ser privado de sua filiação (AA, 2017, p.98).

A garantia de filiação pressupõe uma isenção nas discussões internas e públicas. Este modo de engajamento ausente de exigências e não punitivo enfatiza o laço fraterno e tenta minimizar os efeitos de paternidade e liderança, situação comum nos mais variados agrupamentos sociais. Se considerarmos que a coletividade dos AA segue o modelo das massas, enquanto um grupo organizado, cabe interrogar qual o seu modo de identificação predominante. 
O tratamento teórico empreendido por Lacan sobre a identificação destaca do texto freudiano a função do traço unário definindo este como a condição de surgimento do significante. Diferente do signo, que implica um sentido particular, é próprio do significante apontar para a diferença. O surgimento do traço remonta aos primórdios da escrita e de sua função na constituição do sujeito. Lacan, conta que ao visitar o Museu de Saint-Germain se depara com uma costela de animal pré-histórico marcada por vários traços verticais e sequenciais. Isto faz com que ele conjecture sobre o que poderia indicar essas inscrições, por exemplo a quantidade animais abatidos em uma caçada. Independente do significado dessas inscrições, vemos aí a função do traço como marca fundamental do "um" da diferença e não de unicidade. Disso, pode-se chegar a consideração que a identificação conduz a distinção e não a indiferenciação.

Um traço notório de distinção no sujeito diz respeito a sua relação com o nome próprio. A forma de grafar, escrever o nome seria o que há de mais singular em cada sujeito, muito embora a nomeação é própria do Outro. Em outras palavras, não se escolhe o nome próprio, sendo que este em geral antecipa o nascimento do humano. Importante considerar que o sujeito receba via transmissão cultural o seu nome patronímico (sobrenome), ou em alguns casos o mesmo prenome do pai, cabendo a cada um elaborar, portanto, algo de singular dessa condição.

Considerando a função do traço unário, do significante e do nome, a leitura lacaniana da obra freudiana sintetiza a identificação também em três modos: a identificação com o pai, a identificação com o traço e a identificação histérica. Seguindo as descobertas freudianas o destaque lacaniano reside na operatividade do desejo. Assim, a 'infecção psíquica' descrita por Freud é lida por Lacan como uma identificação histérica ou imaginária. Esta modalidade de identificação implica uma via desejante, já que se apropriar do desejo do outro como seu próprio é um dos traços estruturais da histeria.

A identificação com a 'doença alcoólica' de um alcoólico anônimo corresponde ao primeiro dos doze passos do programa terapêutico da Irmandade. Em seguida, a convocação do Outro e a invocação de seu nome revela o estabelecimento de uma demanda de sobriedade dirigida ao Outro. Não obstante, a sustentação dessa lógica alienante se apoia no enlaçamento com os outros semelhantes 'doentes alcoólicos em recuperação' através do 'desejo de parar de beber' (terceira tradição) e de uma contínua construção narrativa de si:

Como consequência, os membros do grupo reafirmam seu pertencimento ao A.A., introjetando seu modelo terapêutico, revivendo-o a cada narrativa. As reuniões de recuperação são, portanto, verdadeiros rituais terapêuticos, capazes de permitir aos AA ressignificar suas experiências, dentro de uma ordem simbólica na qual elas adquirem sentido (Campos, 2010, p.114). 
Se o nome próprio do sujeito é um indicativo de sua marca de singularidade, o que dizer da condição de anonimato almejada pelos AA? É recorrente na literatura a justificativa do anonimato como uma dupla função: proteger o 'alcoólico em recuperação' da exclusão social (no que se refere as ofertas de trabalho, por exemplo) e na contínua operação desconstrução de um Eu ('egocentrismo' conforme a literatura) em favor de uma nova reinserção social. Nomear-se como anônimo é também sinalizar para uma posição subjetiva que toma a via segregação. Uma comunidade de anônimos visa demarcar um lugar diferenciado no laço social conforme a "lógica do condomínio" com suas exigentes regras internas de funcionamento e delimitações próprias como conjunto social (Dunker, 2015).

Dessa forma, pertencer aos AA implica, conforme sua literatura, na construção de modo de vida que busca uma reinserção ao laço social através de uma posição deficitária e patológica:

[...] preferimos dizer que o diagnóstico incide sobre uma forma de vida, e cada um desses aspectos é apenas uma perspectiva de determinada forma de vida. Diagnosticar é reconstruir uma forma de vida, definida pelo modo como esta lida com a perda da experiência e com a experiência da perda (Dunker, 2015, p. 282).

A identidade patológica 'alcoólico anônimo' pode ser considerada, portanto, como uma forma de vida. Tal conceito é originário da filosofia de Agamben (2014) quando este situa a ascese monástica franciscana da época medieval como uma prática de padronização e formatação da vida a um conjunto de regras cotidianas. Passados os séculos, vivenciamos o surgimento de formas de vida fundamentadas não propriamente nas religiões, mas nas categorias médicas, sobretudo, as psicopatológicas. A forma de vida dos AA, conforme difundida em sua literatura, visa à manutenção diária da abstinência alcoólica através de um conjunto de exercícios, técnicas de evitação, orações, partilhamentos, acompanhamento e monitoramento dos padrinhos, citações de jargões ('só por hoje') e de trechos da literatura (AA, 2005). Um dos efeitos diretos dessa forma de vida é o aprisionamento do sujeito em uma temporalidade presente, buscando uma diferença radical com o passado etílico.

Uma forma de vida fabricada a partir da prática de um ethos dietético requer uma garantia do Outro institucional e de uma verdade da doença e do tratamento. Disso, a crença doutrinária expressa na literatura oficial tende a uma posição fundamentalista unindo o saber a verdade.

\section{CONSIDERAÇõES FINAIS}

Para os AA, a recuperação do alcoolismo é possível se o alcoolista 
reconstruir seu laço social em torno dos ideais do Eu da vida civilizada (família, trabalho, casamento) e construir uma nova alteridade (vertical com o Outro e horizontal com o outro semelhante) na comunidade de anônimos.

Nem propriamente uma religião (apesar do empuxo a esta), nem irmandade no sentido clássico (como a maçonaria) e nem ainda um movimento político identitário (como o feminismo ou movimento negro). A distinção dos AA no contexto das inúmeras coletividades surgidas na passagem dos séculos XIX ao XX foi de inserir a identidade patológica como traço de coletividade. Nisso, recuperar a discussão freudiana sobre a formação das massas nos mostra um movimento típico da contemporaneidade qual seja a multiplicação e a diversidade dos grupos identitários.

No caso dos $A A$, enquanto instituição, a elaboração das doze tradições de $A A$ segue o propósito de assegurar uma identificação pela via da categorização diagnóstica e histérica, cuja funcionalidade extrapola a terapêutica e se apresenta como um significante mestre discursivo. Ser membro de AA é recorrer aos significantes do Outro institucional, sobretudo, a literatura oficial. Nos chama a atenção que nessa construção do alcoólico anônimo o texto escrito possua um lugar central. A escrita e a leitura da literatura de AA compõem um grande tecido simbólico, cuja função é recobrir o objeto bebida alcoólica.

Assim, a busca por um laço de coletividade, servindo de amparo, denota a funcionalidade de um ethos dietético ou de uma forma de vida em torno do objeto proibido. A bebida alcoólica enquanto objeto parece se sobrepor ao sujeito que elege como saída uma posição de dependência e alienação a um Outro construído. Em termos discursivos, o surgimento da identidade 'alcoólico anônimo' indica a operatividade de um discurso que não faz laço em função do gozo com o objeto: o discurso do capitalista. Se a adicção é a consequência maior desse discurso de exceção, a novidade dos AA foi a de construir a identidade do adicto e sua comunidade.

\section{REFERÊNCIAS}

Alcoólicos Anônimos. (2009). Alcoólicos Anônimos Atinge a Maioridade: uma breve história de A.A. São Paulo: JUNAAB (Trabalho original publicado em 1957).

Alcoólicos Anônimos. (2010). Alcoólicos Anônimos: como milhares de homens e mulheres se recuperaram do alcoolismo. São Paulo: JUNAAB. (Trabalho original publicado em 1939).

Alcoólicos Anônimos (2017). Na Opinião de Bill: o modo de vida dos AA. São Paulo: JUNAAB (Trabalho original publicado em 1967).

Askofaré, S. (2009). Aspectos da Segregação. São Paulo: Revista a Peste, 1(2), 345-354.

Assoun, P.L. (2008). Freud e as Ciências Sociais: psicanálise e teoria da cultura. São Paulo: Edições Loyola.

Barros, L.S; Danziato, L. (2014). Das Relações Entre Identificação e Nomeação: o sujeito e o significante. Revista Subjetividades, 14(1), 53-61.

Campos, E.A. de. (2010). "Nosso Remédio É a Palavra": uma etnografia sobre o modelo terapêutico de Alcoólicos Anônimos. Rio de Janeiro: Editora Fiocruz.

Costa, R.M.L da; Danziato,L. (2020). O lugar da crença no programa terapêutico da Irmandade Alcoólicos Anônimos: um estudo psicanalítico. Revista Tempo Psicanalítico, 53(1), 216-242. 
Dunker, C.I.L. (2015). Mal-estar, Sofrimento e Sintoma: uma psicopatologia do Brasil entre muros. São Paulo: Boitempo. (Coleção Estado de Sítio).

Dunker, C. I. L, Paulon, C. P, \& Mílan-Ramos, J. G. (2016). Análise Psicanalítica de Discurso: perspectivas lacanianas. São Paulo: Estação das Letras e das Cores.

Figueiredo, L.C. (2007). A Invenção do Psicológico: quatro séculos de subjetivação, 1500 a 1900 (7ª ed.). São Paulo: Escuta.

Foucault, M. (2007). Vigiar e Punir: o nascimento da prisão. Rio de Janeiro: Editora Vozes.

Freud, S. (2010). Obras Completas, volume 18: O mal-estar na civilização, novas conferências introdutórias à psicanálise e outros textos (1930/1936). (Paulo César de Souza Trad.). São Paulo: Companhia das Letras.

Freud, S. (2011). Obras Completas, volume 15: Psicologia das Massas e Análise do Eu e Outros Textos (1920-1923). Tradução: Paulo César de Souza. São Paulo. Companhia das Letras.

Freud, S. (2012). Obras Completas, volume 11: Totem e Tabu, Contribuições à História do Movimento Psicanalítico e Outros Textos (1912-1914). (Paulo César de Souza Trad.). São Paulo: Companhia das Letras.

Lacan, J. (1992). O Seminário, livro 17: O Avesso da Psicanálise. Seminário dos anos de 1969-70. Rio de Janeiro: Jorge Zahar.

Lacan, J. (1998). O Seminário, livro 11: Os Quatro conceitos Fundamentais da Psicanálise. Rio de Janeiro: Jorge Zahar.

Lacan, J. (2003). Outros Escritos. Rio de Janeiro: Jorge Zahar.

Lacan, J. (2008). O Seminário, livro 08: A Transferência. Rio de Janeiro: Jorge Zahar.

Lacan, J. (2014). A Identificação. Seminário (1961-1962). Recife: Centro de Estudos Freudianos do Recife (publicação não comercial).

Lebrun, J.P. (2009). A Clínica da Instituição: o que a psicanálise contribui para a vida coletiva. Porto Alegre: CMC Editora.

Orllandi, E.P. (2005). Análise do Discurso: princípios e procedimentos. São Paulo: Editora Pontes.

Kehl, M.R (Org.). (2000). A Função Fraterna. Rio de janeiro: Relume Dumará.

Kehl, M.R. (2004). Subjetividade, Psicologia e Direitos humanos. In: Conselho Federal de Psicologia Psicologia e Direitos Humanos: subjetividade e exclusão. São Paulo: Casa do Psicólogo, Brasília, DF: Conselho Federal de Psicologia.

Tadvald, M. (2006). Serenos, Corajosos e Sábios: a plataforma terapêutica dos Alcoólicos Anônimos e de seus participantes através do olhar antropológico (Dissertação de mestrado). Universidade Federal do Rio Grande do Sul - UFRGS, Porto Alegre, Rio Grande do Sul, Brasil.

Trois, J. F. de M. (1998). A cura pelo espelho: uma leitura antropológica do dispositivo terapêutico dos grupos de auto-ajuda de Neuróticos Anônimos (Dissertação de mestrado). Universidade Federal do Rio Grande do Sul - UFRGS, Porto Alegre, Rio Grande do Sul, Brasil.

Vegh, I. (2005). O Próximo: enlaces e desenlaces do gozo. Rio de Janeiro: Companhia de Freud.

\section{SOBRE OS AUTORES}

Raul Max Lucas da Costa é psicanalista, membro do Aleph - Escola de Psicanálise. Mestre em História Social pela Universidade Federal do Ceará-UFC. Doutor em Psicologia pela Universidade de Fortaleza-UNIFOR. Professor do curso de Psicologia do Centro Universitário Dr. Leão Sampaio-UNILEÃO, Juazeiro do Norte-CE.

E-mail: raulmax@leaosampaio.edu.br.

(D) https://orcid.org/0000-0002-6283-4890

Leonardo Danziato é psicanalista e professor universitário. Professor Doutor Titular, do Programa de PósGraduação em Psicologia da Universidade de Fortaleza (UNIFOR).

E-mail: leonardodanziato@unifor.br.

(6) https://orcid.org/0000-0002-8870-9123 